\title{
Removal of chloride from harbor oily sludge by electrostatic desalting
}

\author{
Y.-J. Huang ${ }^{1}$, C.-H. Tu$^{2} \&$ Y. C. Huang ${ }^{3}$ \\ ${ }^{I}$ Department of Biomedical Engineering and Environmental Sciences, \\ National Tsing Hua University, Taiwan \\ ${ }^{2}$ Department of Occupational Safety and Health, \\ Chung Hwa College of Medical Technology, Taiwan \\ ${ }^{3}$ Department of Environmental Engineering, \\ National Cheng Kung University, Taiwan
}

\section{Abstract}

The object of this study is to remove the chloride from harbor oily waste by an electrostatic desalting process before it is recovered. The pyrolysis kinetics of emulsified desalted harbor oily sludge were also determined to realize the properties of emulsified desalted harbor oily sludge in thermal treatment.

In experiments, the concentration of chloride in the harbor oily waste decreased from 55.7 to $50.1 \mathrm{ppm}$ by using the electrostatic desalting process while the amount of desalter was $20 \mathrm{ppm}$ and reaction time was 1 hour. However, the desalting efficiency was increased by increasing the amount of desalter. The chloride in the harbor oily waste would be decreased to $35.0 \mathrm{ppm}$ by adding $50 \mathrm{ppm}$ of desalter during the reaction time in 20 minutes.

The three-stage pyrolysis of the harbor oily sludge was found in the thermal gravimetric analysis (TGA) process. The equations for pyrolysis of the harbor oily sludge in the first and second stages can be expressed as $\mathrm{dx}_{1} / \mathrm{dt} \quad\left(\mathrm{sec}^{-1}\right)=3.6 \times 10^{5}\left(\mathrm{sec}^{-1}\right) \quad \exp \left(-16084\left(\mathrm{calmol}^{-1}\right) / \mathrm{R}\left(\mathrm{calmol}^{-1} \mathrm{~K}^{-1}\right) \mathrm{T}(\mathrm{K})\right)(1-\mathrm{x})^{0.46}$ ( $\mathrm{x}$ denotes the reaction conversion) and $\mathrm{dx}_{2} / \mathrm{dt}=1.1 \times 10^{7} \exp (-21883 / \mathrm{RT})(1-\mathrm{x})^{0.02}$, respectively. The equations for pyrolysis of the emulsified desalted harbor oily sludge in the first and second stages can be expressed as $\mathrm{dx}_{1} / \mathrm{dt}=5.0 \times 10^{7}$ $\times \exp (-17609 / \mathrm{RT}) \quad(1-\mathrm{x})^{0.27} \quad(\mathrm{x}$ denotes the reaction conversion $)$ and $\mathrm{dx}_{2} / \mathrm{dt}=7.6 \times 10^{8} \exp (-26460 / \mathrm{RT})(1-\mathrm{x})^{0.07}$, respectively.

Keywords: harbor oily sludge, chloride, emulsification, pyrolysis, kinetics. 


\section{Introduction}

Marine transportation is highly developed in Taiwan. Taiwan also plays a significant role in world transportation. Each international harbor in Taiwan is bound with multiple functions as transportation, sightseeing and business. However, the most important thing is to maintain the view and environmental hygiene of these harbor areas. The sludge in the bottom of harbor areas and the waste produce from ships should be cleaned up efficiently so as to meet the current environmental standards.

According to the MARPOL 73/78, the oily waste's treatment equipment should be set in the harbor areas. Taiwan authorities try to treat the oily wastes properly and solve the waste problems effectively [1, 2]. Recently, the waste oily sludge recovered technology including heat treatment process, press filtration, solvent extraction process, centrifugal process and sludge combustion emulsified process $[3,4]$ were studied.

However, harbor oily waste is commonly produced as a water-in-oil emulsion with large quantities of dissolved and particulate matters. These impurities are normally found to be the chloride salts of calcium, magnesium and sodium as well as solids such as silt, iron sulfides and other crystalline salts. If these contaminants remained in the harbor oily waste, they would lead to such problems as follows: the chloride salts contained in the harbor oily waste would decompose to form hydrochloric acid which will result in severe corrosion problems at high temperatures in the furnace; certain impurities may poison catalysts; solid particles could deposit on heat exchanger tubes while reducing heat transfer rates; sodium may act as a catalyst for coke formation in transfer line and exchanger tubes. Thus, these impurities (especially chloride salts) should be removed before these waste oil sludge is recovered.

The salts in oil usually disperse to sediment. In fact, the sediment is a stable layer of emulsion, which is surrounded by the emulsification of asphalt, resin and suspended solids. Many of the impurities in the harbor oily waste are insoluble. It is believed that these impurities can be separated from the harbor oily waste by a liquid-liquid phase separation process. Thus, wash water is used to make soluble these impurities. The wash water and oily sludge would be emulsified and form fine water droplets in the oil. The stabilization of the emulsion depends on the surface tension of water and oil, viscosity of oil, quantity of water, the level of emulsification and the size of droplets. In order to prevent the salt water residing in the oil, coalescence of droplets form large heavy droplets to separate from the harbor oily waste quickly by adding a demulsifier, using electrostatic and raising temperature. Chemical demulsifiers have the ability to overcome the surface toughness of drops and allow colliding drops to coalesce. The movement of water in the electric field has been recognized [5] and can be used in the desalting process for the separation of oil and water. Besides, the viscosity of harbor oily sludge could be decreased by raising the temperature.

Harbor oily sludge also contains a large amount of combustibles with very high heat value. The pyrolysis process of oily sludge has been successfully 
designed and commercialized [6-8]. The oily sludge in Taiwan is used as the raw material of pyrolysis. The heat value of dry basis is about $10681 \mathrm{Kcal} / \mathrm{Kg}$ [9]. The heat value of harbor oily sludge is also high. It was suitable for recovery as fuel oil only if it had been treated properly by eliminating the chloride. Thermogravimetric analysis (TGA) is widely used as a method to investigate the thermal decomposition of the wastes [10-12]. A detailed description of these methods have been given by Friedman [12], Petrovic and Zavargo [13] who have discovered important techniques to evaluate the kinetic parameters from the TGA traces. Thus, the purpose of this study was to remove the chloride salts contained in the harbor oily waste by using the electrostatic desalting process. After the desalting process, harbor oily waste contains a little amount of droplets and they might be added with an emulsifying agent to form the emulsified fuel. The pyrolysis kinetics of an emulsified desalted harbor oily sludge were also studied to reveal the properties of emulsified desalted harbor oily sludge in thermal treatment.

\section{Materials and methods}

\subsection{Materials}

The oily sludge used in this study was obtained from Kaohsiung harbor in Taiwan.

\subsection{Desalting process of harbour oily sludge}

Water (10 vol\%) and desalter (DS-1)(20-60 ppm) were added in the harbor oily sludge $(300 \mathrm{ml})$. In the meantime, an electrolysis process was used to remove the chloride saline from the oil. Titanium electrodes were used and charged by current power supply (30V) for 1 hour. The stir rate was $1500 \mathrm{rpm}$ at $343 \mathrm{~K}$.

\subsection{Pyrolysis kinetics of emulsified desalted harbor oily sludge}

A part of the harbor oil sludge after desalting treatment was added emulsifying agent (TS-3A). Emulsifying agent (TS-3A) was provided by TENS technology company. The added amount of emulsifying agent was $2.5 \mathrm{vol} \%$.

The pyrolysis kinetics of emulsified harbor oily sludge would be studied by using a thermogravimetric analyzer (TGA). About 10-30 mg of sample was heated in nitrogen $(100 \mathrm{ml} / \mathrm{min})$ at different heating rates of 2,5 and $10 \mathrm{~K} / \mathrm{min}$ at $303-973 \mathrm{~K}$ in the TGA experiments. The overall rate equation is expressed in the Arrhenius equation as follows:

$$
\begin{aligned}
& \mathrm{dx} / \mathrm{dt}\left(\mathrm{sec}^{-1}\right)=\mathrm{A}\left(\mathrm{sec}^{-1}\right) \exp \left(-\mathrm{Ea}\left(\mathrm{calmol}^{-1}\right) / \mathrm{R}\left(\mathrm{calmol}^{-1} \mathrm{~K}^{-1}\right) \mathrm{T}(\mathrm{K})\right) \mathrm{f}(\mathrm{x}) \\
& \mathrm{f}(\mathrm{x})=[\mathrm{x}]^{\mathrm{n}} \\
& \mathrm{x} \quad: \text { Weight loss rate }\left(\mathrm{W}_{0}-\mathrm{W}\right) /\left(\mathrm{W}_{0}-\mathrm{W}_{\mathrm{f}}\right) \\
& \mathrm{W}_{0} \quad \text { : Initial weight of waste }(\mathrm{mg}) \\
& \mathrm{W} \quad \text { : Weight of waste at t time }(\mathrm{mg}) \\
& \mathrm{W}_{\mathrm{f}} \quad \text { : Residue weight of waste after reaction }(\mathrm{mg})
\end{aligned}
$$




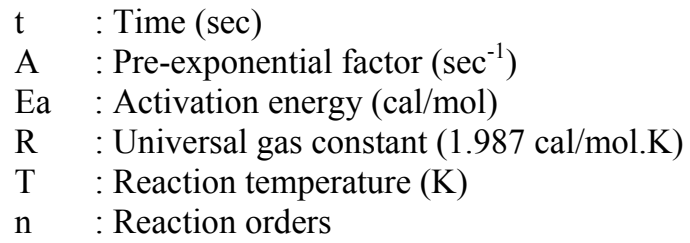

\section{Results and discussion}

\subsection{Fundamental properties analysis for harbor oily sludge}

The fundamental oil properties of harbor oily sludge were shown in Table 1. The density was about $0.9285 \mathrm{Kg} / \mathrm{L}$; the fluidity point was $-15^{\circ} \mathrm{C}$; the viscosity was about $83.44 \mathrm{cSt}$. Although the properties of harbor oily sludge were in accordance with the fuel oil specification, it cannot be used as marine fuel oil. Ash in the harbor oily sludge was higher than marine fuel oil. The value of precipitation was $0.18 \%$ (including the water content and moisture) and the heat value was $10451 \mathrm{cal} / \mathrm{g}$. These properties matched the specification of fuel oil. The heat value was higher than that of the American specification of no. 6 fuel oil (10200 cal/g), so it was very suitable for heat recovery. But the content of chloride in the harbor oily sludge was approximately $55.7 \mathrm{ppm}$ which was higher than fuel oil. Chloride should be removed before the recovery process, otherwise, it will be harmful to the furnace in thermal treatment by using the harbor oily sludge as the fuel oil directly.

\subsection{Desalting process of harbor oily sludge}

In order to remove the chloride, $10 \%$ of wash water was added in the oil. The harbor oily sludge contained high polarize asphaltene and resin. Those contents made oily sludge and wash water emulsify and produce extremely fine water droplet in the oil. At the same time, the suspended solid and the crystallization of salts clustered on the interface layer of oil and water, which made the emulsification more stable. When harbor oily sludge had a high viscosity, it would slow down the separation of droplet from oil. A little amount of demulsifier in the desalting process was put in to accelerate the destruction at the emulsified layer of water and oil. The concentration of chloride in the harbor oily sludge at various amount of desalter (DS-1) in the electrostatic desalting process was shown in Figure 1. While the amount of desalter was $20 \mathrm{ppm}$ (shown in Figure 1(a)), the removal efficiency of dichloride was only $10.1 \%$. The chloride in the harbor oily sludge decreased from $55.7 \mathrm{ppm}$ to $50.1 \mathrm{ppm}$ for one hour. When the desalter increment was up to $30 \mathrm{ppm}$, the chloride in the harbor oily sludge decreased to $34.3 \mathrm{ppm}$. The removal efficiency of chloride was $38.4 \%$. It showed that with the increment of DS-1 desalter, the chloride in oil would be decreased. In addition, the chloride of the harbor oily sludge in the desalting process at $50 \mathrm{ppm}$ of desalter (reaction time was $20 \mathrm{~min}$ ), could be decreased to 
Water Pollution VIII: Modelling, Monitoring and Management 277

\begin{tabular}{|c|c|c|c|c|c|}
\hline 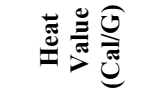 & ' & ' & ' & ' & 突 \\
\hline 爮竞 & ' & ' & ' & ' & $\hat{\dot{q}}$ \\
\hline 离 & $\begin{array}{l}n \\
0 \\
\dot{x} \\
\dot{x}\end{array}$ & 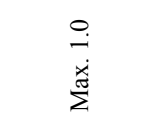 & ' & $\begin{array}{l}n \\
0 \\
\dot{x} \\
\sum\end{array}$ & $\stackrel{\infty}{\stackrel{0}{0}}$ \\
\hline 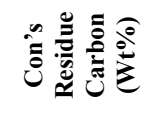 & 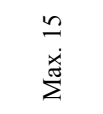 & $\begin{array}{l}n \\
\dot{m} \\
\dot{m}\end{array}$ & $\begin{array}{l}n \\
\dot{x} \\
\stackrel{\dot{x}}{\Sigma}\end{array}$ & $\begin{array}{l}n \\
\dot{x} \\
\stackrel{\dot{x}}{\Sigma}\end{array}$ & $\stackrel{0}{\text { త్ }}$ \\
\hline 产 & ' & ' & ' & . & $\stackrel{\circ}{\stackrel{9}{f}}$ \\
\hline$\frac{a}{e^{\circ}}$ & ' & $\begin{array}{l}-\overrightarrow{0} \\
\dot{x} \\
\dot{x}\end{array}$ & $\begin{array}{l}\overrightarrow{0} \\
\dot{x} \\
\dot{x}\end{array}$ & , & $\underset{⿱}{J}$ \\
\hline 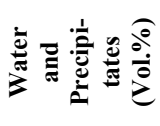 & $\begin{array}{l}\stackrel{0}{+} \\
\stackrel{x}{\dot{m}}\end{array}$ & ' & $\begin{array}{l}\stackrel{0}{\dot{x}} \\
\stackrel{\dot{x}}{\mathrm{~m}}\end{array}$ & $\begin{array}{l}\stackrel{0}{\dot{x}} \\
\stackrel{\dot{x}}{\Sigma}\end{array}$ & $\stackrel{\infty}{\circ}$ \\
\hline 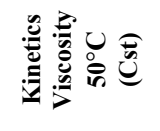 & 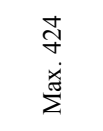 & $\begin{array}{l}\stackrel{\infty}{-} \\
\stackrel{x}{x} \\
\stackrel{\pi}{\Sigma}\end{array}$ & $\begin{array}{l}\infty \\
\stackrel{\infty}{\dot{x}} \\
\dot{e}\end{array}$ & 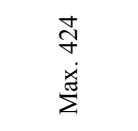 & $\underset{\infty}{+}$ \\
\hline 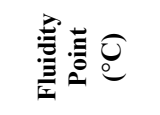 & $\begin{array}{l}n \\
\dot{x} \\
\stackrel{\infty}{\Sigma}\end{array}$ & $\begin{array}{l}\stackrel{\ominus}{e} \\
\dot{x} \\
\dot{x}\end{array}$ & $\begin{array}{l}m \\
\dot{x} \\
\dot{m}\end{array}$ & $\begin{array}{l}n \\
\dot{x} \\
\stackrel{\dot{x}}{\Sigma}\end{array}$ & $\cong$ \\
\hline 咅导 & ' & $\begin{array}{l}0 \\
\dot{n} \\
\dot{x} \\
\dot{m}\end{array}$ & ' & $\begin{array}{l}0 \\
\dot{n} \\
\dot{x} \\
\dot{m}\end{array}$ & $\stackrel{\Xi}{g}$ \\
\hline 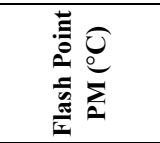 & $\begin{array}{l}8 \\
\dot{5}\end{array}$ & $\begin{array}{l}8 \\
\dot{\Xi}\end{array}$ & $\begin{array}{l}8 \\
\dot{\Xi} \\
\dot{\Xi}\end{array}$ & $\begin{array}{l}8 \\
\dot{B} \\
\dot{\Xi}\end{array}$ & ڤิ \\
\hline 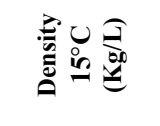 & 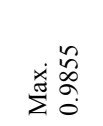 & 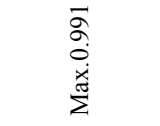 & 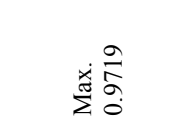 & 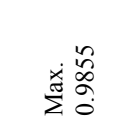 & 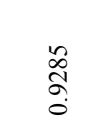 \\
\hline 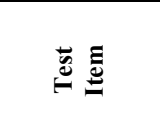 & 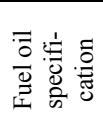 & 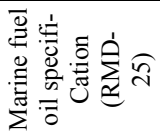 & 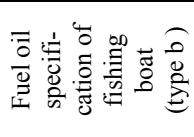 & 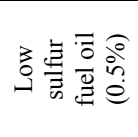 & 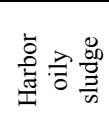 \\
\hline
\end{tabular}


$35.0 \mathrm{ppm}$ which was similar to that at $30 \mathrm{ppm}$ of desalter (reaction time was $60 \mathrm{~min}$ ). If the reaction time was prolonged to $60 \mathrm{~min}$ at $50 \mathrm{ppm}$ of desalter, the chloride in the waste oil could be removed $47.0 \%$ and the chloride was decreased to $29.5 \mathrm{ppm}$. If using only heating and electrostatic treatment of harbor oily sludge, the efficiency of desalting was not good. The desalter would enhance the efficiency of desalting.

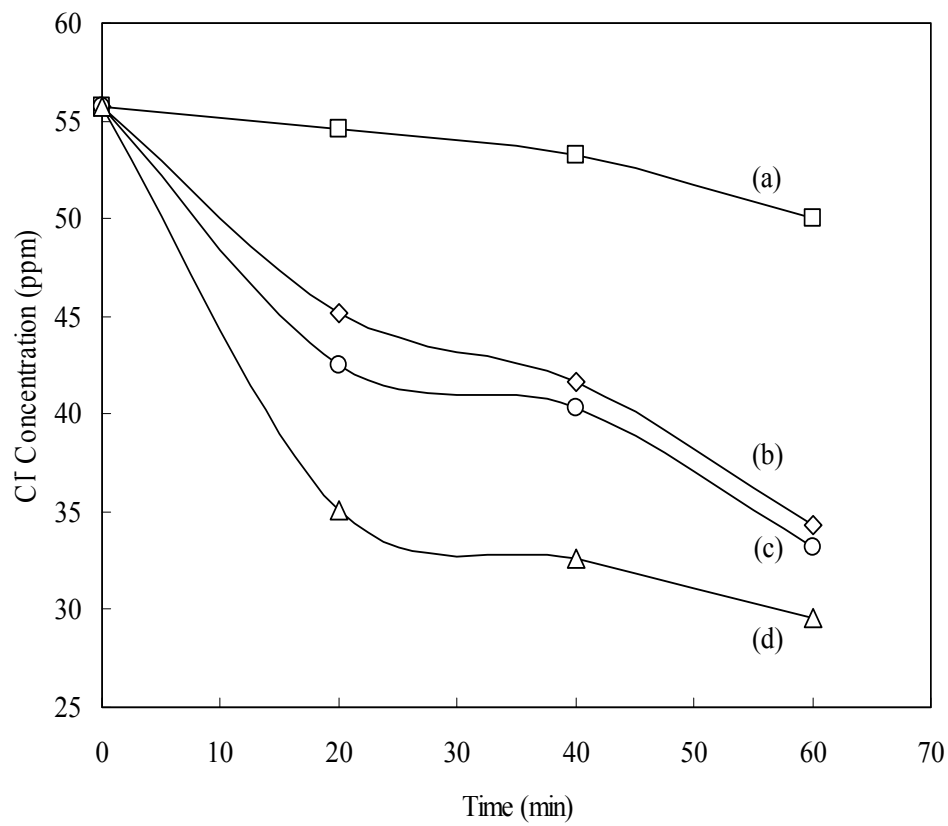

Figure 1: The concentration of chloride in the desalting process of harbor oily sludge at various amounts of desalter (DS-1), (a) $20 \mathrm{ppm}$, (b) $30 \mathrm{ppm}$, (c) $40 \mathrm{ppm}$ and (d) $50 \mathrm{ppm}$. (added 10\% water, reaction temperature $343 \mathrm{~K}$, voltage $30 \mathrm{~V}$ and rate $1500 \mathrm{rpm}$ ).

\subsection{Pyrolysis kinetics of emulsified desalted harbor oily sludge}

After the electrostatic desalting process, there was some water still contained in the harbor oily sludge. If the oil and water were not mixed well, the quality of recovery fuel oil from harbor oily sludge might not be good. Thus, about $2.5 \mathrm{vol} \%$ emulsifying agent was added in the harbor oily sludge (called emulsified desalted harbor oily sludge). However, the properties of emulsified desalted harbor oily sludge in thermal treatment weren't well understood. The pyrolysis kinetics of harbor oily sludge and emulsified desalted harbor oily sludge were studied. The thermogravimetric analysis data of harbor oily sludge and emulsified desalted harbor oily sludge are shown in Figure 2. The curves of TGA of harbor oily sludge and emulsified desalted harbor oily sludge pyrolysis were divided into a three-stage process (weight reduction interval 100-80\%, $79-30 \%$ and $30-3 \%$ ). The maximum weight loss harbor oily sludge occurred at 
437, 636 and $708 \mathrm{~K}$, respectively. The emulsified desalted harbor oily sludge could be decomposed at a lower temperature (max weight loss at 394, 583 and $706 \mathrm{~K}$ ). It was worth mentioning that the residual mass of pyrolysis of harbor oily sludge and emulsified desalted harbor oily sludge was $4.6 \%$ and $3.0 \%$, respectively at $973 \mathrm{~K}$. It may be due to microexplosions to reduce coke formation by secondary-atomization [14].

The pyrolysis kinetics of harbor oily sludge was obtained by Arrhenius equation. At the first and second stage, the weight ratio $\left(\mathrm{W} / \mathrm{W}_{0}\right)$ was $100-80 \%$ and $79-30 \%$; the temperature range was $300-530 \mathrm{~K}$ and $532-650 \mathrm{~K}$. The activation energy of first and second stage was 13-20 and 20-23 Kcal/mol, respectively as well as the mean activation energy was 16.08 and $21.88 \mathrm{Kcal} / \mathrm{mol}$. The reaction order and pre-exponential factor were $0.46,0.02$ and $362580,10875250 \mathrm{sec}^{-1}$, respectively. Therefore, the kinetics equation could be expressed as:

The first stage $\left(\mathrm{W} / \mathrm{W}_{0}: 100-80 \%\right)$

$$
\mathrm{dx}_{1} / \mathrm{dt}=3.6 \times 10^{5} \exp (-16084 / \mathrm{RT})(1-\mathrm{x})^{0.46}
$$

The second stage $\left(\mathrm{W} / \mathrm{W}_{0}: 79-30 \%\right)$

$$
\mathrm{dx}_{2} / \mathrm{dt}=1.1 \times 10^{7} \exp (-21883 / \mathrm{RT})(1-\mathrm{x})^{0.02}
$$

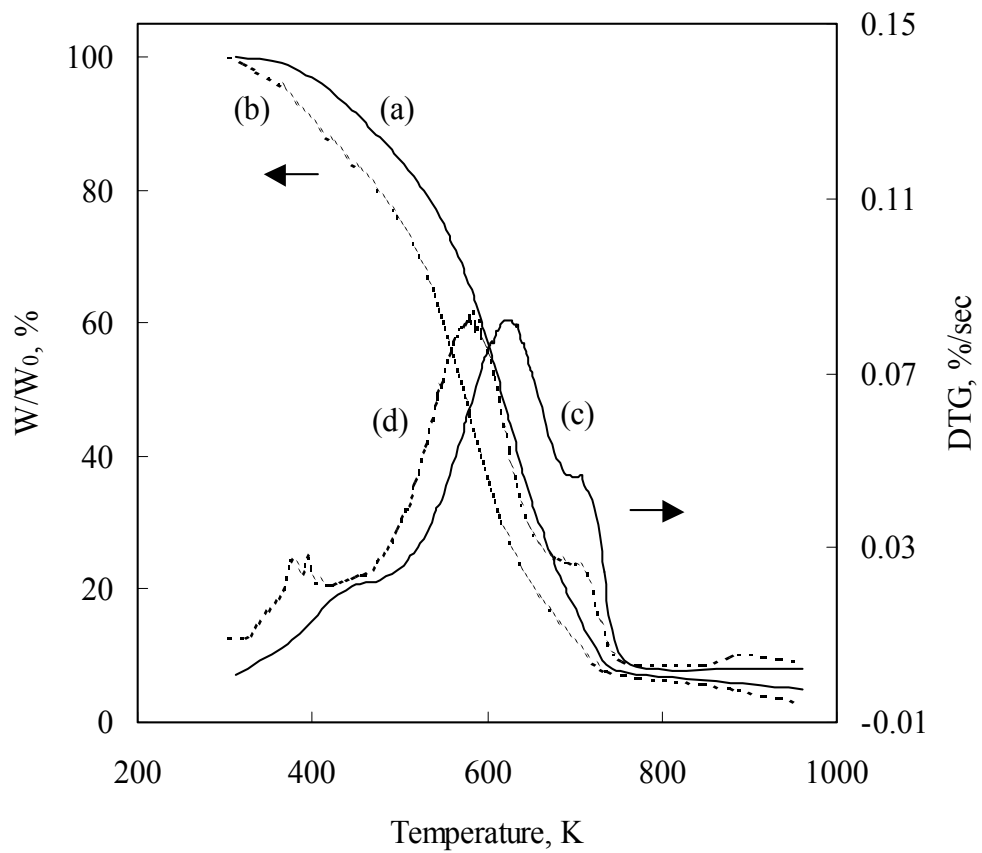

Figure 2: The TGA curves of (a) harbor oily sludge, (b) emulsified desalted harbor oily sludge and the derivatives of TGA curves, (c) harbor oily sludge and (d) emulsified desalted harbor oily sludge. 
Moreover, rate constant $\mathrm{k}$ could be expressed as below:

$$
\begin{gathered}
\mathrm{dx} / \mathrm{dt}=\mathrm{k}(1-\mathrm{x})^{\mathrm{n}}\left[\mathrm{O}_{2}\right]^{\mathrm{m}} \\
\mathrm{k}=\mathrm{A} \exp (-\mathrm{Ea} / \mathrm{RT}) \\
\ln \mathrm{k}=\ln \mathrm{A}-\mathrm{Ea} / \mathrm{RT}
\end{gathered}
$$

So, equation (4) and (5) could be expressed as

$$
\begin{aligned}
& \ln k=12.801-8.09 \times(1000 / T) \\
& \ln k=16.202-11.01 \times(1000 / T)
\end{aligned}
$$

The pyrolysis of emulsified desalted harbor oily sludge at the first and second stage weight ratio $\left(\mathrm{W} / \mathrm{W}_{0}\right)$ was $100-80 \%$ and $79-30 \%$; the temperature range was $300-473 \mathrm{~K}$, and $479-615 \mathrm{~K}$. The Ea value of first and second stage was between $15-20$ and $23-31 \mathrm{Kcal} / \mathrm{mol}$, respectively as well as the mean value was 17.61 and $26.46 \mathrm{Kcal} / \mathrm{mol}$. By the way, the reaction order and pre-exponential factor were $0.27,0.07$ as well as $50324369,758611237 \mathrm{sec}^{-1}$, respectively. So the kinetics equation can be shown as:

The first stage $\left(\mathrm{W} / \mathrm{W}_{0}: 100-80 \%\right)$

$$
\mathrm{dx}_{1} / \mathrm{dt}=5.0 \times 10^{7} \exp (-17609 / \mathrm{RT})(1-\mathrm{x})^{0.27}
$$

The second stage $\left(\mathrm{W} / \mathrm{W}_{0}: 79-30 \%\right)$

$$
\mathrm{dx}_{2} / \mathrm{dt}=7.6 \times 10^{8} \exp (-26460 / \mathrm{RT})(1-\mathrm{x})^{0.07}
$$

Otherwise, rate constant $\mathrm{k}$ also could be expressed as below :

$$
\begin{aligned}
& \operatorname{lnk}=17.73-8.87 \times(1000 / \mathrm{T}) \\
& \ln \mathrm{k}=20.44-13.32 \times(1000 / \mathrm{T})
\end{aligned}
$$

Although, the activation energy of emulsified desalted harbor oily sludge were higher than that of harbor oily sludge between the first and second stage. The lower peak temperature and less amount of residue generated might decrease the formation of $\mathrm{NO}_{\mathrm{x}}$ and emission of particulate pollutants from the thermal treatment of emulsified desalted harbor oily sludge. It is still of great worth that the emulsified desalted harbor oily sludge could be recovered as fuel oil to improve the environmental protection or apply to the energy development.

\section{Conclusions}

From the detection of fundamental properties for the harbor oily sludge, it could be known that the water and precipitation were in accordance with fuel oil specifications. It was suitable for recovery as fuel oil only if it had been treated properly by eliminating the chloride.

When the amount of desalter DS-1 was $20 \mathrm{ppm}$, the chloride in the harbor oily sludge decreased from $55.7 \mathrm{ppm}$ to $50.1 \mathrm{ppm}$ in electrostatic desalting process for one hour. The removal efficiency of chloride was approximately $10.1 \%$. When the desalter was increased to $50 \mathrm{ppm}$, the chloride in the waste oil 
could be removed $47.0 \%$ and the chloride was decreased to $29.5 \mathrm{ppm}$. With an incremental increase of the desalter, the removal efficiency of chloride would be increased.

The thermogravimetric analysis data showed that the emulsified desalted harbor oily sludge could be decomposed at a lower temperature than the harbor oily sludge. The residual mass of pyrolysis of emulsified desalted harbor oily sludge was also lower than that of pyrolysis of harbor oily sludge at $973 \mathrm{~K}$. The global rate equations for pyrolysis of the harbor oily waste in the first and second stages could be expressed as $\mathrm{dx}_{1} / \mathrm{dt}=3.6 \times 10^{5} \exp (-16084 / \mathrm{RT})(1-\mathrm{x})^{0.46}$ and $\mathrm{dx}_{2} / \mathrm{dt}=$ $1.1 \times 10^{7} \exp (-21883 / \mathrm{RT})(1-\mathrm{x})^{0.02}$, respectively. The equations for pyrolysis of the emulsified waste fuel in the first and second stages could be expressed as $\mathrm{dx}_{1} / \mathrm{dt}=5.0 \times 10^{7} \exp (-17609 / \mathrm{RT})(1-\mathrm{x})^{0.27}$ and $\mathrm{dx}_{2} / \mathrm{dt}=7.6 \times 10^{8} \exp (-26460 / \mathrm{RT})(1-$ $\mathrm{x})^{0.07}$, respectively. Although, the activation energy of emulsified desalted harbor oily sludge was higher than that of harbor sludge, the lower decomposition temperature and less residue after pyrolysis would still make the emulsified desalted harbor oily sludge suitable as fuel oil.

\section{References}

[1] Ebara Corporation, 2001. Proposal of Taiwan Kaoshsing Harbor/Oilsludge treatment.

[2] Integrated Environmental Technologies LLC., 2001. Process to Treat 48 Ton/Day Oily Sludge Waste of Bureau of Kaohsing Harbor with Plasma Enhanced Melter.

[3] Werther, J. \& Ogada, T., Sewage sludge combustion. Progress in Energy and Combustion Science, 25(1), pp. 55-116, 1999.

[4] Kufferath, A., Ehrhardt, K., Heyse, C. \& Leuckel, W., Continuous generation and air-assisted atomization of fuel oil-water-emulsions. Combustion Science and Technology, 148(1-6), pp. 17-26, 1999.

[5] Ottosen, L.M., Hansen, H.K., Laursen, S. \& Villumsen, A., Electrodialytic Remediation of Soil Polluted with Copper from Wood Preservation Industry. Environmental Science and Technology, 31(6), pp. 1711-1715, 1997.

[6] Ayen, R.J. \& Swanstrom, C.P., Low temperature thermal treatment of petroleum refinery waste sludges. Environmental Progress, 11(2), pp. 127-133, 1992.

[7] Steger, M.T. \& Meibner, W. Drying and low temperature conversion-a process combination to treat sewage sludge obtained from oil refineries. Water Science and Technology, 34(10), pp. 133-139, 1996.

[8] Swanberg, C., MX-2500 thermal processor for the treatment of petroleum refining wastes and contaminated soils. Environmental Progress, 12(2), pp. 160-162, 1993.

[9] Shie, J.L., Chang, C.Y., Lin, J.P., Wu C.H. \& Lee, D.J., Resources recovery of oil sludge by pyrolysis: kinetics study. Journal of Chemical Technology and Biotechnology, 75(6), pp. 443-450, 2000. 
[10] Huang, Y. J., Wang, H. P., Liu, S. H. \& Hsiao, M. C., Pyrolysis kinetics of spent low-level radioactive resin. Nuclear Technology, 138(2), pp. 206-210, 2002.

[11] Chen, K.S., Yeh, R.Z., \& Wu, C.H., Kinetics of thermal decomposition of epoxy resin in nitrogen-oxygen atmosphere. Journal of Environmental Engineering-ASCE123, 123(10), pp. 1041-1046, 1997.

[12] Friedman, H.L., Kinetics of thermal degradation of char-forming plastics from thermogravimetry, application to a phenolic plastic. Journal of Polymer Science Part C, 6, pp. 183, 1965.

[13] Petrovis, Z.S. \& Zavargo, Z.Z., Reliability of Methods for Determination of Kinetic Parameters from Thermogravimetry and DSC Measurements. Journal of Polymer Science, 32(4), pp. 4353-4367, 1986.

[14] Ballester, J.M., Fueyo N. \& Dopazo, C., Detailed Measurements in Heavy Oil and Oil/Water Emulsion Flames. Combustion Science and Technology, 106(4-6), pp. 383-391, 1995. 